\title{
Special Issue "The Reasonable Interpreter. Perspectives on Legal and Non-Legal Semiotics". Introduction
}

\author{
Angela Condello ${ }^{1} \cdot$ Paolo Heritier ${ }^{2} \cdot$ Massimo Leone $^{3,4} \cdot$ Jenny Ponzo ${ }^{3}$
}

Accepted: 15 August 2020 / Published online: 8 October 2020

(C) Springer Nature B.V. 2020

The origin of the present issue lies in a number of questions which intersect both the fields of semiotics and of legal philosophy and theory, especially concerning the nature and function of languages, and the function of reasonableness and interpretation in the balancing of conflicting values. Can we consider semiotics as an autonomous discipline, with its own objects, issues and methods-or should we (instead) consider it as a field of study, a catalogue of undetermined and undefined interests, uneasy to be made homogeneous and to reunify? ${ }^{1}$ Following the last option, questions that are structural for semiotics are, for instance, at the core of the legal operations and of both traditional and innovative approaches to legal theory and practice. With such transdisciplinary attitude, we imagined a double-sided Roundtable (Turin, 19-20 September 2020), with participants working both in semiotics and legal philosophy, aimed at delving into questions such as: What is the role of reasonableness in legal hermeneutics today? Is the digital revolution having an impact on the production of legal knowledge and-if so-can semiotics enrich the analysis of such impact and transformation? In other words: how are legal and non-legal semiotics connected today? And can this relationship be traced back to antiquity? What is the relationship between the semioticians' legal semiotics and jurists' legal semiotics?

Stemming from such origin, and against the background of the abovementioned problems, the papers gathered in this issue, all presented in the occasion of the Turin Roundtable, touch upon the intersection of disciplinary fields as well as of themes and questions all aligned in a way or another around the core semiotic grammar of the perennial movement between signs, objects, and interpretants—which has often

\footnotetext{
${ }^{1}[1: 18]$.
}

Angela Condello

acondello@unime.it

1 University of Messina, Messina, Italy

2 Eastern Piedmont University, Vercelli, Italy

3 University of Turin, Turin, Italy

4 Shanghai University, Shanghai, China 
been neglected by legal theory and which, instead, proves to be essential for a thorough understanding of the cultural and societal progression of legal knowledge.

Inasmuch as the semiotic approach has proved fruitful for the legal theorists involved in this project, the realm of legal normativity revealed to be of specific interest from the perspective of semiotics because the objects of the law evolve through dynamics between signifiers and meanings. The intersectional nature of our experiment emerges from the style and questions addressed by the authors, who all-with diverse objectives but with similar intentions-managed to confront the links between language and normativity, some with specific reference to the current transformations impacting society through digital revolutions, and some with reference to (apparently) less timely themes that contributed to root solidly the present discussion about reasonableness.

In the process of formation of the issue, three axes have taken shape: (1) semiotics; (2) legal theory; (3) legal semiotics. The first axis (1) includes the contributions of Ugo Volli, Massimo Leone, Jenny Ponzo, Annamaria Lorusso, and Gabriele Vissio. Volli addresses the role of the reasonable interpreter within the Talmudic tradition, distinguishing reasonableness and rationality and underlining the necessary nature of the latter. In Leone's contribution we encounter a critical analysis on the limits of digital interpretation with reference to the transition from semantic to syntactic connectedness. Jenny Ponzo's contributes a semiotic reading of the legal language of Canon law, specifically as regards a new case for sainthood recently introduced by the Catholic Church in its canonization trials, "the offering of life"; Lorusso's paper challenges the contemporary regime of post-truth through questions of legitimacy in public discourse as related to truth-production processes. Vissio's piece explores Canguilhem's philosophical language in relation to the notion of "vital normativity", which defines human beings as the only living beings capable of reasoning on the base of values.

Along the second axis, the collection includes papers addressing more traditional legal-theoretical problems in their interconnection with the core question of reasonableness. Simões Gaudêncio addresses the reciprocal implication of rationality and reasonableness in legal argumentation and logic; her contribution is complemented by both Amorim's piece on the (im)possibility to describe interpretive reasonableness in the law, on the one hand, and, on the other hand, by Labi's article on Saul Kripke's comments on Wittgenstein's Philosophical Investigations as regards their relevance for legal interpretation. Along this second axis, Leszczyński's contribution bears on the role of extra-legal values in judicial interpretation.

Finally, the collection also unfolds along a third axis, comprising the contributions of Ricca, Heritier, Messner, Condello, and Campo, all somehow attempting to explore the intersectional space between the two first axes. Ricca's article develops remarks on the specific reasonableness of the law and its creative force to produce re-configurations of reality which go across established categories; Heritier identifies the primacy of legal semiotics of jurists starting from Trabant's semiotic work on Giambattista Vico; Messner deals with the concreteness and materiality of the digital revolution, which is (re)shaping various concepts of language, community, and justice-and the consequent need for legal interpreters to become speakers of a language enabling interaction among diverse voices and grammars. Condello's 
piece is a discussion on the identity of legal reasoning and reasonableness, meant as a practice of prudence and judgement that today, in light of the digital revolution, must be addressed as both a grammatological and a hermeneutic transition. Campo points at the metaphorical nature of the reasoning about big data and the ideal to which data-based knowledge (dataism) aims.

Thus, the concept of reasonableness and the methodological status of legal semiotics become, in the present issue of the International Journal for the Semiotics of Law, elements that outline a complex horizon in the background of the emerging question of the transformation that the digital revolution implies in both fields.

\section{Reference}

1. Eco, Umberto. 1975. Trattato di semiotica generale. Milano: Bompiani.

Publisher's Note Springer Nature remains neutral with regard to jurisdictional claims in published maps and institutional affiliations. 